\title{
Evaluation of clinical and demographic characteristics of Turkish and Syrian pediatric cutaneous leishmaniasis patients from Hatay, Turkey after the Syrian civil war
}

\author{
Ozlem Makbule Kayaํㅜ, Gamze Serarslan², Emre Dirican ${ }^{3}$
}

1Department of Parasitology, Faculty of Medicine, Mustafa Kemal University, Hatay/Antakya, Turkey ${ }^{2}$ Department of Dermatology, Faculty of Medicine, Mustafa Kemal University, Hatay/Antakya, Turkey ${ }^{3}$ Department of Biostatistics, Faculty of Medicine, Mustafa Kemal University, Hatay/Antakya, Turkey

Adv Dermatol Allergol 2020; XXXVII (2): 229-233

DOI: https://doi.org/10.5114/ada.2018.79729

\begin{abstract}
Introduction: Cutaneous leishmaniasis $(\mathrm{CL})$ is a skin disease affecting all ages but especially children. Cutaneous leishmaniasis exists in Turkey, and, especially together with emigration from Syria to Turkey in recent years due to the civil war in Syria, the incidence of the disease has increased.

Aim: To investigate Syrian patients (SP) and Turkish patients (TP) in the pediatric age group who were diagnosed with $\mathrm{CL}$ and to compare the age, gender, clinical type, number of lesions, and lesion localizations of these patients. Material and methods: We included CL patients aged 0-18 who were admitted to the outpatient clinic in the period 2015-2017 and in the first half of 2018. A total of 121 patients (SP, $n=87 ;$ TP, $n=34$ ) were included in the study. Results: The mean ages of TP and SP were $12.06 \pm 4.47$ and $8.68 \pm 5.18$ years and the disease durations were 6.25 \pm 3.86 and $4.73 \pm 3.39$ months respectively $(p=0.049$ ). The total number of lesions was 247 . The mean lesion number per child was $2.35 \pm 2.28$ in SP, and $1.23 \pm 0.55$ in TP $(p=0.002)$. Two and multiple lesions were significantly higher in SP $(p=0.005)$. It was found that the lesions were most frequently located in the head/neck $(\mathrm{HN})$ region $(76.9 \%)$ and $44.1 \%$ of patients with HN localization belonged to the $7-12$ age group. We also found that $57.1 \%$ of the HN lesions were of the papule type in the patients.

Conclusions: We obtained similar results as in other studies in terms of age, gender, localization, and duration of lesions in general. When SP and TP were compared, we found that the number of lesions was higher, the disease duration was shorter, and the mean age was younger in SP.
\end{abstract}

Key words: cutaneous leishmaniasis, pediatric, Syria, Turkey.

\section{Introduction}

Cutaneous leishmaniasis $(\mathrm{CL})$ is the disease caused by Leishmania spp., an intracellular parasite. More than $70 \%$ of all CL cases are seen in 10 countries worldwide, which are Afghanistan, Algeria, Brazil, Colombia, Costa Rica, Ethiopia, the Islamic Republic of Iran, Peru, Sudan, and the Syrian Arab Republic [1]. It was reported that the causative agents of the disease are L. tropica and L. major in Syria [2, 3].

Turkey is one of the countries where $C L$ is also prevalent [1]. Studies conducted in Turkey have shown that the predominant causative agent of CL is L. tropica [4]. Cutaneous leishmaniasis is endemic in Turkey, especially in the Southeast and the Mediterranean region [5]. Howev- er, in the last 5-6 years, many Syrian people have immigrated to Turkey due to the civil war in Syria. As a result, the incidence of the disease has increased considerably, especially in the areas of intense emigration [6, 7]. Hatay province of Turkey, located in the Mediterranean region, is one of the cities most affected by the migration due to its border with Syria.

Cutaneous leishmaniasis is more common especially in the childhood and young age group ( $0-20$ years of age) $[8,9]$. Although the studies reported from Turkey previously described the clinical and demographic data of the disease, a relatively small number of studies have focused on this age group in detail [10].

Address for correspondence: Prof. Gamze Serarslan, Department of Dermatology, Faculty of Medicine, Mustafa Kemal University, 31100 Hatay/Antakya, Turkey, fax: +90 05332482790, e-mail: gserarslan@hotmail.com Received: 11.09.2018, accepted: 17.10.2018. 


\section{Aim}

The aim of this retrospective study was to evaluate the clinical and demographic data of Syrian immigrant and Turkish children diagnosed with $\mathrm{CL}$, who were consulted in our Dermatology Outpatient Clinic, and to compare Syrian patients (SP) and Turkish patients (TP) with respect to age, gender, disease duration, and localization, number and type of lesions. So far, this is the first study in which pediatric CL patients from the Hatay region have been examined in detail.

\section{Material and methods}

In the present study, we included $\mathrm{CL}$ patients aged 0-18 years and recorded their clinical and demographic data. The patients were admitted to our outpatient clinic in the period 2015-2017 and in the first half of 2018. A total of 121 patients (55 (63.2\%) male, 32 (36.8\%) female SP; 19 (55.88\%) male and 15 (44.1\%) female TP) were included in the study. The diagnosis of CL was made by showing parasites in the smears taken from the lesions. Demographic and clinical data of patients were recorded from patient files. Statistical analysis was performed by dividing the patients into 0-6, 7-12, and 13-18 age groups.

\section{Statistical analysis}

Data were analyzed using SPSS for Windows (version 21; IBM Corp, Armonk, New York, USA), $\chi^{2}$, Kruskal-Wallis, Mann-Whitney $U$, and Yates's continuity correction tests were used for statistical analysis. Values were presented as the mean \pm standard deviation and $p<0.05$ was considered as significant.

\section{Results}

Patients' ages ranged from 1 to 18 years (mean: 9.63 \pm 5.2 ). The mean ages of TP and SP were $12.06 \pm 4.47$ (3-18 years) and $8.68 \pm 5.18$ (1-18 years) respectively. Fifty percent of the TP were in the 13-18 age group, and 39\% of the SP were in the $7-12$ age group (Table 1). There was no relationship between age groups and gender in all patients $(p=0.629)$. The SP and TP also did not show any relationship regarding gender and age group within themselves (SP $p=0.644$, TP $p=0.460$ ).

Table 1. Distribution of TP and SP by age group and gender

\begin{tabular}{lccccccc}
\hline \multirow{2}{*}{ Age } & \multicolumn{2}{c}{ TP } & \multicolumn{3}{c}{ SP } & Total \\
\cline { 2 - 8 } & Male & Female & $\%$ & Male & Female & $\%$ & $n(\%)$ \\
\hline $0-6$ & 3 & 2 & 14.7 & 19 & 14 & 38 & $38(31.4)$ \\
\hline $7-12$ & 5 & 7 & 35.3 & 22 & 12 & 39 & $46(38)$ \\
\hline $13-18$ & 11 & 6 & 50 & 14 & 6 & 23 & $37(30.6)$ \\
\hline Total & 19 & 15 & 100 & 55 & 32 & 100 & $121(100)$ \\
\hline
\end{tabular}

The average disease duration was $5.15 \pm 3.57$ months (range: 1 week-12 months) (definition of "disease duration": the time period between the appearance of the first lesion and the arrival of the patient at the hospital for examination). There was no significant difference between the age groups regarding disease duration $(p=0.943)$. The disease durations in SP and TP were 1 week-12 months (mean: $4.73 \pm 3.39$ months) and 1-12 months (mean: $6.25 \pm 3.86$ months) respectively $(p=0.049)$. In the same analysis, we did not include the disease durations of 6 patients because when the outlier analysis was performed, the disease duration was deflecting. The disease durations of these patients were in the range 30-60 months and 4 of them were SP while 2 of them were TP.

The total number of lesions was 247 ( $n=42$ in TP, $n=205$ in SP), and the mean number of lesions per patient was $2.04 \pm 2.01$. There was one lesion in $61.2 \%$ of the patients and 2 lesions in $19.8 \%$ of the patients. When TP and SP were analyzed separately, $82.4 \%(n=28)$ of the TP had one lesion, $11.8 \%(n=4)$ had 2 lesions, and $5.9 \%(n=2)$ had 3 lesions, while $52.9 \%(n=46)$ of SP had one lesion, $23 \%(n=20)$ had 2 lesions, and $23.9 \%$ $(n=21)$ had $\geq 3$ lesions. Although there was no statistically significant difference between the age groups in terms of number of lesions ( $p=0.207$, Kruskal-Wallis test), the mean number of lesions was the highest in the $7-12$ age group $(2.54 \pm 2.43)$. When TP and SP were evaluated within themselves, mean lesion number was 2.35 \pm 2.28 (1-11 lesions) in SP, and $1.23 \pm 0.55$ ( $1-3$ lesions) in TP. Between two groups, the number of lesions per patient was significantly higher in SP $(p=0.002)$ compared to TP and two and multiple lesions were significantly higher in SP ( $p=0.005)$. Regarding age group, when TP and SP were evaluated separately, the number of lesions in SP was the highest in the 7-12 age group (mean: 3.029, $p=0.049$ ). This was followed by the $13-18$ age group. There was no significant difference with respect to number of lesions in all three age groups of TP $(p=0.653$; Bonferroni corrected Mann-Whitney $U$ test) (Table 2).

It was found that the lesions were most frequently located in the head/neck $(H N)$ region $(n=93,76.9 \%)$ in the patients. $44.1 \%(n=41)$ of the patients with HN localization were in the $7-12$ age group. This was followed by the age groups $0-6(32.3 \%, n=30)$ and $13-18(23.7 \%, n=22)$. When the age groups of SP and TP were evaluated within themselves, HN localization was most frequently observed in the $7-12$ age group in both groups (SP; $n=29,42.6 \%$; TP; $n=12,48 \%$ ). This was followed by the 0-6 age group in SP, and the 13-18 age group in TP. When the SP and TP were compared in terms of location of the lesions, it was found that the localization of HN was more frequent in TP than in SP $(73.5 \%$ and $59.8 \%$ respectively, $p=0.05)$. We found that $57.1 \%$ of the HN lesions were of the papule type. In addition, $63.6 \%(n=7)$ of the extremity-localized lesions were of the ulcer type. Clinical samples are shown 
in Figure 1. When SP and TP were evaluated separately, again the most common type of lesion was papule (with $52.9 \%$ and $55.9 \%$ respectively; for both $p=0.001$ ).

The cheek area lesions in both patient groups have the highest frequency (SP 19.5\%, TP 19\%). Diffuse infiltration was present in 3 of the patients with lip lesions. The localization and the number of the lesions in TP and SP are shown in Figure 2 and the distribution of lesion types is shown in Table 3.

\section{Discussion}

Although CL occurs at all ages, it is most common among children and teenagers $[6,10,11]$. In our study, we found that the mean age of TP was significantly higher than SP. This difference in our study may be due to the difference between the numbers of patients in both groups as well as the higher recognition of the disease among SP. The most frequently affected age group in our study was 7-12 in SP and 13-18 in TP. It has been previously reported that $\mathrm{CL}$ disease was more frequently observed between the ages of 11-15 [12] and 13-24 [13] in Hatay province where all age groups were included in these studies, which is also compatible with our study. Uzun et al. reported that the disease was most commonly seen in the 10-19 age group [8]. In another study comprising the $0-15$ age group, the $6-10$ age group was identified as the most infected group [10]. If we look at the results of other studies comprising pediatric age groups bearing $C L$ in Iran and Tunisia, we see that 6-9
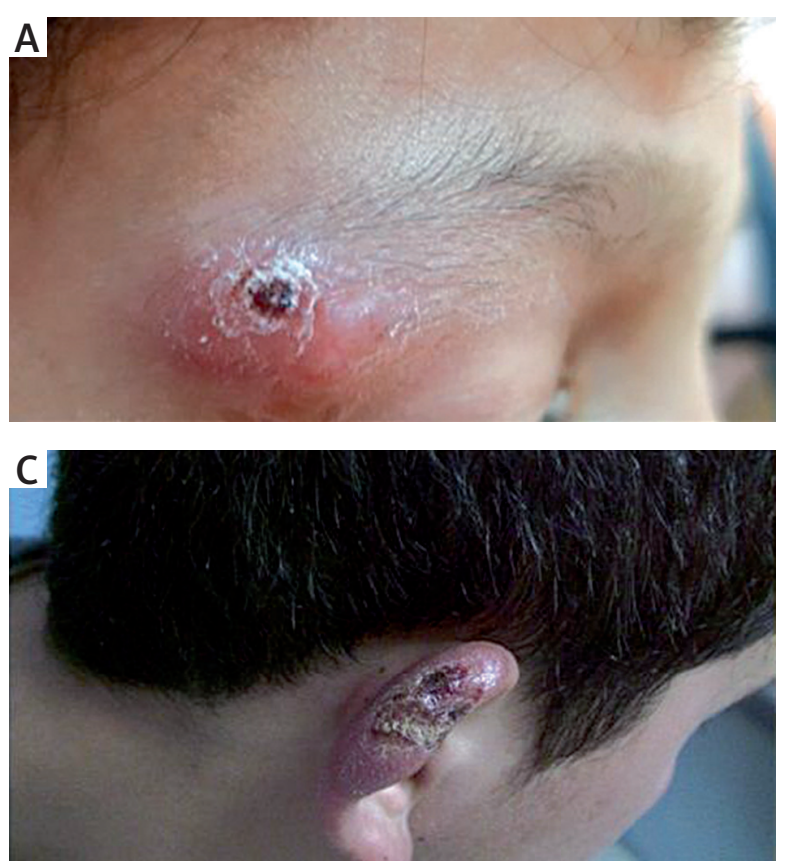

Figure 1. A - A nodule located in the periorbital region, B - multiple nodules of hand, C - ulcerated lesion in the ear, D - A papule located on the chin
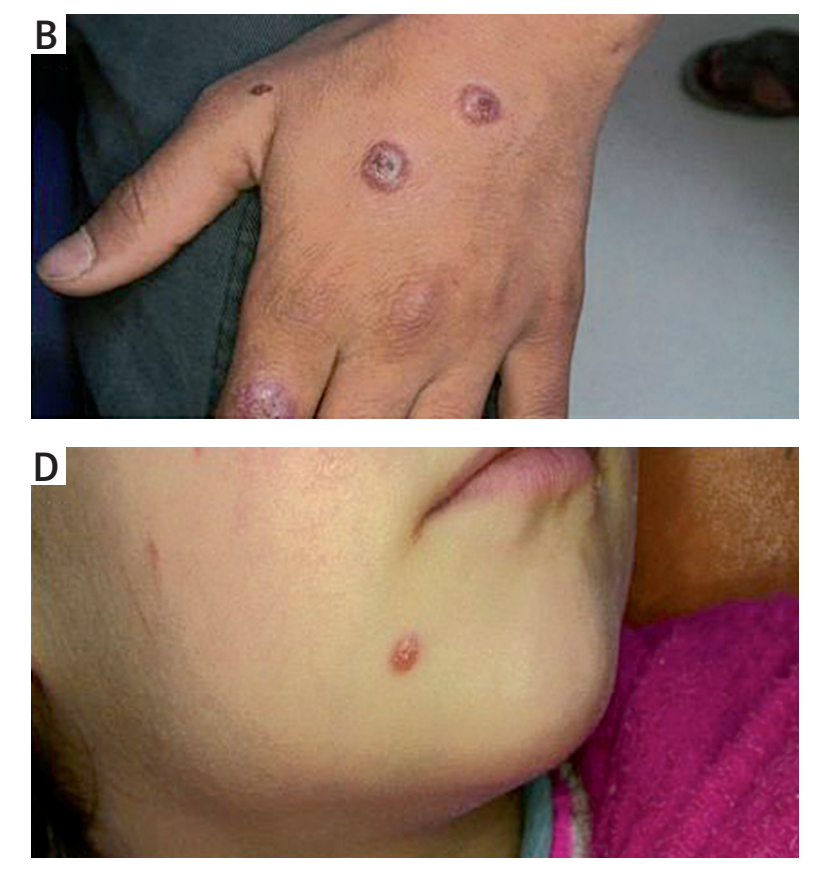
age groups

\begin{tabular}{|c|c|c|c|c|c|}
\hline Group & $\begin{array}{l}\text { Age } \\
\text { groups }\end{array}$ & $\begin{array}{l}\text { Lesion } \\
\text { number }\end{array}$ & Mean \pm SD & $p_{1}$ & $p_{2}$ \\
\hline \multicolumn{6}{|l|}{ SP } \\
\hline & $0-6$ & 50 & $1.51 \pm 0.795$ & \multirow{4}{*}{0.049} & \multirow{9}{*}{0.002} \\
\hline & $7-12$ & 103 & $3.02 \pm 2.657$ & & \\
\hline & $13-18$ & 52 & $2.60 \pm 2.854$ & & \\
\hline & Total & 205 & $2.35 \pm 2.282$ & & \\
\hline \multirow[t]{5}{*}{ TP } & & & & \multirow{5}{*}{0.653} & \\
\hline & $0-6$ & 7 & $1.40 \pm 0.894$ & & \\
\hline & $7-12$ & 14 & $1.16 \pm 0.577$ & & \\
\hline & $13-18$ & 21 & $1.23 \pm 0.437$ & & \\
\hline & Total & 42 & $1.23 \pm 0.553$ & & \\
\hline \multicolumn{2}{|c|}{ Overall total } & 247 & $2.04 \pm 2.018$ & & \\
\hline
\end{tabular}

p1-number of lesions according to age groups in Syrian and Turkish patients, p2 - evaluation of lesion numbers of Syrian and Turkish patients.

[14] and 6-15 age groups [15], respectively, were more frequently affected.

Among our patients, gender was homogeneously distributed within all age groups. Some of the reports conducted in these age groups are consistent with our results [11]. However, Aksoy et al. reported that $\mathrm{CL}$ was more frequently present in females [10].

We found that the disease duration in our study was significantly shorter in SP than in TP (SP: $4.73 \pm 3.39$
Table 2. Distribution of number of lesions according to 

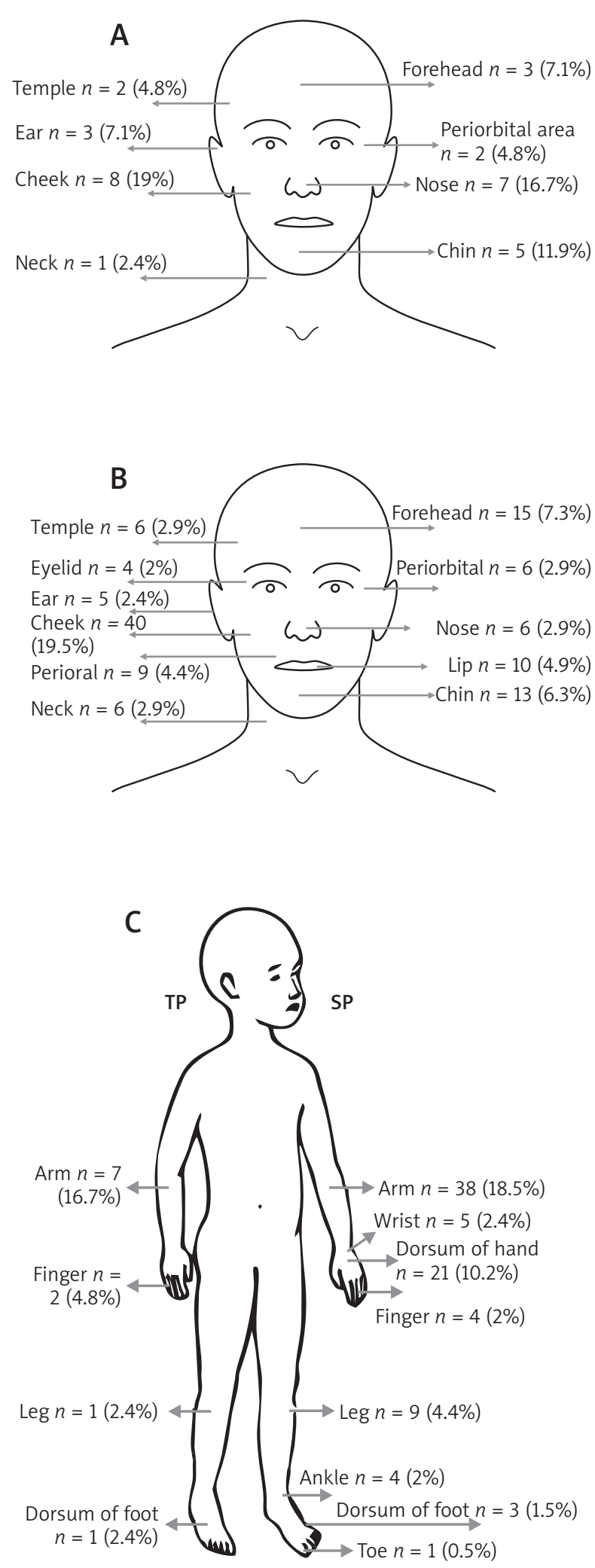

Figure 2. A - Distribution of lesions located in $\mathrm{HN}$ region in TP, B - distribution of lesions located in $\mathrm{HN}$ region in SP, $\mathrm{C}$ - distribution of lesions located in extremities in TP and SP months, TP: $6.25 \pm 3.86$ months). We did not find any difference in the disease duration among the age groups. However, Aksoy et al. reported that the 0-5 age group had the longest disease duration [10].

In our study, the average number of lesions per patient was $2.04 \pm 2.01$. However, when the groups were compared, the mean number of lesions in SP was 2.35 \pm 2.28 , while it was $1.23 \pm 0.55$ in TP $(p=0.002) .82 .4 \%$ of TP and $52.9 \%$ of SP had only one lesion and two and multiple lesions were significantly higher in SP $(p=0.005)$. Our results concerning TP were consistent with the results of Aksoy et al. and Gürel's et al. studies reported from Turkey $[10,11]$. The results of the studies carried out in other countries involving the pediatric age group are as follows: a study in Pakistan reported that $75 \%$ of patients had a single lesion and the mean number of lesions per patient was $1.43 .16 .6 \%$ of patients had two lesions and $8.3 \%$ of patients had > 2 lesions [16]. In India, a single lesion (72.2\%) was most frequently detected in the $0-5$ age group of patients. The authors reported that $19.9 \%$ of patients had two lesions and $7.9 \%$ of patients had multiple lesions [17]. In another study from Iran, only one lesion was detected in $82.3 \%$ of patients, two lesions were detected in $12.4 \%$ of patients, and $\geq 3$ lesions were detected in $5.3 \%$ of patients [18]. When the results of studies reported from other countries as well as Turkey were evaluated, the number of patients with multiple lesions was higher in SP $(23 \%$ of patients had two lesions and $23.9 \%$ of patients had $\geq 3$ lesions). This may be due to inadequate shelter, a crowded environment, and lack of hygiene caused by adverse conditions of migration.

Similar to the results of other studies, it was determined that the HN site was the most common localization of CL in our study $[10,14,15]$. When assessed according to age groups, $44.1 \%(n=41)$ of patients with $\mathrm{HN}$ localization were in the 7-12 age group. Aksoy et al. reported that $\mathrm{HN}$ localization was more frequently observed in the 0-5 age group [10]. In our study, the cheek area was the part where $C L$ was most frequently localized in both SP and TP. In other studies conducted with the childhood age group, it has been reported that the cheek is the region most frequently affected by CL [14-16]. The cheek was proposed to be the area most exposed and the least protected from sandfly bites [16].

In our study, papules were the most common type of lesions and most frequently seen in the $7-12$ age group. $57.1 \%$ of the HN lesions were of the papule type. Another interesting result of our study is that in $63.6 \%(n=7)$ of patients with ulcer type the lesions occurred on extremities. When other studies were reviewed, it was observed that papules [14], plaques [16], plaques or papulonodules [17] or ulcers [10] were reported as the most common types of lesions.

In a study conducted by Turan et al., the number of lesions was higher and disease duration was shorter in 
Table 3. Distribution of lesion types according to age group

\begin{tabular}{lcccccc}
\hline Group & Age group & $\begin{array}{c}\text { Papule } \\
n(\%)\end{array}$ & $\begin{array}{c}\text { Nodule } \\
(\%)\end{array}$ & $\begin{array}{c}\text { Plaque } \\
(\%)\end{array}$ & $\begin{array}{c}\text { Ulcer } \\
(\%)\end{array}$ & $\begin{array}{c}\text { Other* } \\
(\%)\end{array}$ \\
\hline TP & $0-6$ & $1(14.28)$ & $1(14.29)$ & $4(57.14)$ & $1(14.29)$ & - \\
\cline { 2 - 7 } & $7-12$ & $14(93.33)$ & - & $1(6.67)$ & - & - \\
\hline SP & $13-18$ & $8(40.00)$ & $6(30.00)$ & $4(20.00)$ & $2(10.00)$ & - \\
\hline & $0-6$ & $28(56.00)$ & $6(12.00)$ & $11(22.00)$ & $4(8.00)$ & $1(2.00)$ \\
\hline Total & $7-12$ & $85(76.58)$ & $9(8.11)$ & $10(9.01)$ & $5(4.50)$ & $2(1.80)$ \\
\hline
\end{tabular}

SP, similar to the results of our study [18]. In our study, we also found that the papular type of CL lesion was frequent in both TP and SP. Turan et al. reported that nodules were more common in SP whereas ulcers were more frequent in TP [19]. Another study from the same region of Turkey reported that ulcers were the more common type of CL lesions [10]. This may be because of the difference in the species of microorganism that causes $\mathrm{CL}$.

\section{Conclusions}

In the present study, we obtained results similar to previous studies in terms of age, gender, and the localization and duration of CL lesions in general. When SP and TP were compared, we found that the number of lesions was higher, disease duration was shorter, and the mean age was lower in SP.

\section{Acknowledgments}

The illustrations in Figure 2 are taken from the following internet addresses:

https://www.rch.org.au/uploadedlmages/Main/Content/clinicalguide/guideline_index/adult-head-front-andback.gif (Head/neck)).

https://www.rch.org.au/uploadedlmages/Main/Content/clinicalguide/guideline_index/anterior-body-fromthe-right.gif (Body).

\section{Conflict of interest}

The authors declare no conflict of interest.

\section{References}

1. WHO. Leishmaniasis in high-burden countries: an epidemiological update based on data reported in 2014. Wkly Epidemiol Rec 2016; 91: 287-96.

2. Sara I, Rahmo A, Maarouf M. Cutaneous leishmaniasis in Syria. IJPSR 2014; 5: 1362-6.

3. Al-Nahhas S, Altawil A. Leishmaniasis in Syria. Int I Cell Sci Mol Biol 2017; 3: 555609.

4. Gürel MS, Yeşilova Y, Ölgen MK, Özbel Y. Cutaneous leishmaniasis in Turkey. Turkiye Parazitol Derg 2012; 36: 121-9.
5. Ok ÜZ, Balcıoğlu iC, Özkan AT, et al. Leishmaniasis in Turkey. Acta Tropica 2002; 84: 43-8.

6. Inci R, Öztürk P, Mülayim MK, et al. Effect of the Syrian civil war on prevalence of cutaneous leishmaniasis in Southeastern Anatolia, Turkey. Med Sci Monit 2015; 21: 2100-4.

7. Salman is, Vural A, Ünver A, Saçar S. Cutaneous leishmaniasis cases in Nizip, Turkey after the Syrian civil war. Mikrobiyol Bul 2014; 48: 106-13.

8. Uzun S, Uslular C, Yücel A, et al. Cutaneous leishmaniasis: evolution of 3074 cases in the Çukurova region of Turkey. Br J Dermatol 1999; 140: 347-50.

9. Aksoy M, Yeşilova Y, Sürücü HA, et al. The sociodemographic, living and environmental characteristics of patients with cutaneous leishmaniasis. J Turk Acad Dermatol 2017; 11: 17111 1.1.

10. Aksoy M, Doni N, Ozkul HU, et al. Pediatric cutaneous leishmaniasis in an endemic region in Turkey: a retrospective analysis of 8786 cases during 1998-2014. PLoS Negl Trop Dis 2016; 10: e0004835.

11. Gürel MS, Ulukanlıgil M, Ozbilge H. Cutaaneous leishmaniasis in Sanliurfa: epidemiologic and clinical features of the last four years (1997-2000). Int J Dermatol 2002; 41: 32-7.

12. Akçalı C, Çulha G, inalöz HS, et al. Cutaneous leishmaniasis in Hatay. J Turk Acad Dermatol 2007; 1: 1-5.

13. Çulha G, Doğramacı ÇA, Gülkan B, Savaş N. Cutaneous leishmaniasis and its status in Hatay province, Turkey. Turk Hij Den Biyol Derg 2014; 71: 171-8.

14. Layegh P, Moghiman T, Hoseini SAA. Children and cutaneous leishmaniasis: a clinical report and review. J Infect Dev Ctries 2013; 7: 614-7.

15. Kharfi M, Benmously R, Fekih NE, et al. Childhood leishmaniasis: report of 106 cases. Dermatol Online J 2004; 10: 6.

16. Bari AU. Childhood cutaneous leishmaniasis. J Clin Diagn Res 2008; 2: 973-8.

17. Agrawal S, Khandelwal K, Bumb RA, et al. Short report: pediatric cutaneous leishmaniasis in an endemic region in India. Am J Trop Med Hyg 2014; 91: 901-4.

18. Sharifi I, Fekri AR, Aflatonian MR, et al. Cutaneous leishmaniasis in primary school children in the south-eastern Iranian city of Bam, 1994-95. Bull World Health Organ 1998; 76: 289-93.

19. Turan E, Yeşilova Y, Sürücü HA, et al. A comparison of demographic and clinical characteristics of Syrian and Turkish patients with cutaneous leishmaniasis. An J Trop Med Hyg 2015; 93: 559-63. 